\title{
Methylnaltrexone or laxatives for the Management of Opioid-induced Constipation among Palliative Patients on Opioid Therapy: Evidence- based Review
}

\author{
Nezar ASS ${ }^{1}$, Abdallah AK $^{2 *}$ and Nusairat A $^{3}$ \\ ${ }^{1}$ Dubai Hospital, The UEA \\ ${ }^{2}$ Faculty of Nursing, Psychiatric and Mental Health, The Hashemite University, Jordan \\ 3Jordanian Royal Medical Services, Jordan
}

\begin{abstract}
Constipation is a common symptom in advanced cancer patients. Studies have demonstrated that 40 to $80 \%$ of patients on a palliative care service have constipation, this proportion increases to $\geq 90 \%$ when patients are treated with opioids. Opioids are very effective analgesics, frequently prescribed in cancer pain, despite proven analgesic efficacy; the use of opioids is commonly associated with frequently dose-limiting constipation that seriously impacts on patients' quality of life, almost all patients on opioids report constipation as the major side-effect. The aim of this article is to determine the effectiveness of methylnaltrexone and laxatives in the management of opioidinduced constipation among cancer patients in palliative care setting, with focus on randomized clinical trials. A comprehensive and extensive online database search of Science Direct Database, PubMed, Springer Online Database, and HINARI/WHO Database was conducted; also reference lists of related studies were searched, six studies fulfilling the inclusion criteria from 1991 to 2009 were selected and formed the basis for this paper. In three studies the laxatives lactulose, senna, co danthramer, misrakasneham, and magnesium hydroxide with liquid paraffin were evaluated, in three methylnaltrexone. In studies comparing the different laxatives evidence was inconclusive. Evidence on subcutaneous methylnaltrexone was clearer; evidence on laxatives for management of constipation remains limited due to insufficient RCTs. Ultimately it can be suggested from the data presented here that subcutaneous methylnaltrexone is effective in inducing laxation in palliative care patients with opioid-induced constipation and where conventional laxatives have failed.
\end{abstract}

Keywords: Opioid-induced constipation, Methylnaltrexone, Laxatives, Cancer, Management

\section{Introduction}

Constipation is a common symptom in advanced cancer patients. Studies have demonstrated that 40 to $80 \%$ of patients on a palliative care service have constipation. This proportion increases to $\geq 90 \%$ when patients are treated with opioids [1-5]. Fredericks, Hollis and Stricker, [6-10] defines constipation as less than three defecations per week (or change from usual pattern), or the subjective symptom of difficult, infrequent, or incomplete passage of stool that occurs in up to $90 \%$ of patients with advanced cancer receiving opioids and can negatively impact pain management and quality of life, almost all patients on opioids report constipation as the major side-effect. A hospital survey showed that $87 \%$ of patients on strong opioids required the use of laxatives. Among patients using morphine $80 \%$ reported constipation.

When opiates bind to the opiate receptors in the GI tract, they interfere with peristalsis and the mucous secretion required for bowel movements [11-15]. Use of exogenous opioids reduces peristalsis. Which, together with reduced secretion, increased liquid reabsorption, and increased sphincter tone, leads to the formation of dry, hard stools which are difficult to pass [16].

The impact of constipation on patients' quality of life is important, especially for cancer patients [17]. Whose quality of life is already significantly impaired by the illness itself, constipation has been deemed by cancer patients to be an even greater source of discomfort than the pain they suffered. According to world health organization (WHO), Opioids are very effective analgesics, frequently prescribed in cancer pain [18]. Despite proven analgesic efficacy, the use of opioids is commonly associated with frequently dose-limiting constipation that seriously impacts on patients' quality of life [19]. In addition to its negative impact on quality of life, persistent constipation may lead to serious medical squeal, including bowel obstruction and faecal impaction; may result in elevated use of prescription drugs and medical services; and may affect compliance with pain medications, further compromising pain management strategies.

Therefore The purpose of this evidence-based review was to answer the following PICOT question for an intervention/therapy, where $(\mathrm{P})$ stand for the population and primary problem, (I) stand for intervention, $(\mathrm{C})$ stand for comparison, $(\mathrm{O})$ stand for outcome, and $(\mathrm{T})$ stand for time it takes to achieve an outcome:

In patients with OIC, and they are cared within the palliative care unit $(\mathrm{P})$, what is the effect of methylnaltrexone (I) on the management of OIC (O) compared with laxatives (C) within 24 hours after administration $(\mathrm{T})$ ?

\section{Method}

Articles were retrieved for review via a combination of computer

*Corresponding author: Abdallah AK, Clinical instructor, Psychiatric and Mental Health, The Hashemite University, Jordan, Tel: 962772313135; E-mail: abu_keet@yahoo.com

Received February 25, 2016; Accepted July 12, 2016; Published July 24, 2016

Citation: Nezar ASS, Abdallah AK, Nusairat A (2016) Methylnaltrexone or laxatives for the Management of Opioid-induced Constipation among Palliative Patients on Opioid Therapy: Evidence-based Review. Adv Practice Nurs 2:121. doi: 10.4172/2573-0347.1000121

Copyright: $\odot 2016$ Nezar ASS, et al. This is an open-access article distributed under the terms of the Creative Commons Attribution License, which permits unrestricted use, distribution, and reproduction in any medium, provided the original author and source are credited. 
Citation: Nezar ASS, Abdallah AK, Nusairat A (2016) Methylnaltrexone or laxatives for the Management of Opioid-induced Constipation among Palliative Patients on Opioid Therapy: Evidence-based Review. Adv Practice Nurs 2:121. doi: 10.4172/2573-0347.1000121

Page 2 of 4

and manual searches of selected opioid-induced constipation and cancer-related publications. A comprehensive, and extensive online database search of Science Direct Database, PubMed, Springer Online Database, and HINARI/WHO Database was conducted for opioid-induced constipation, keywords used were "opioid-induced constipation" "methylnaltrexone", "laxatives", "cancer", "management" in multiple combination. Also reference lists of related studies were searched.

The review utilized 6 articles despite extensive search which met the inclusion criteria. The inclusion criteria were: 1 . Randomized clinical trials (RCTs) 2. It investigated opioid-induced constipation 3. Studies concerned adult participants receiving palliative care. Based on this inclusion criteria a total of 6 articles from 1991 to 2009 were selected and formed the basis for this review.

Level of evidence of the included studies rated based on the work of Melnyk et al., as level two of evidence (Table 1).

The six RCTs analyzed 498 participants, one study were of crossover design; the others were parallel design, of which three were multi-center. The studies were undertaken in North American, British, Spanish and Indian populations. All participants were at an advanced stage of disease and were cared within a palliative care setting; most participants had a cancer diagnosis. The average age of participants ranged from 61 to 72 years.

The drugs assessed were subcutaneous methylnaltrexone and the laxatives, all taken orally, were senna; danthron combined with poloxamer. One study also evaluated the effect of misrakasneham; a drug used in traditional Indian medicine as a purgative, containing castor oil, ghee, milk and 21 kinds of herbs. In the studies on methylnaltrexone nearly all participants ( $88 \%$ to $99 \%$ ) were constipated at entry despite taking one or more conventional laxatives.

\section{Findings}

Descriptions of included studies in the review displayed through Table 2 .

Co-danthramer versus Senna plus Lactulose: One cross-over study of 51 participants evaluated the effectiveness of co-danthramer versus senna plus lactulose. Both laxatives were in a liquid format.

Laxation responses: The researcher reports that participants receiving $80 \mathrm{mg}$ or more of strong opioid had a significantly higher stool frequency when taking lactulose plus senna than while receiving co-danthramer. While in a lower dose of opioid, no statistical difference was reported.

Constipation-associated symptoms, pain intensity, opioid withdrawal: Not evaluated.

Acceptability and tolerability: Diarrhea resulted in suspension of laxative therapy for 24 hours for 15 patients taking lactulose and for five patients taking codanthramer. Researcher report that six instances of diarrhea occurred at opioid doses of at least $80 \mathrm{mg}$ /day while taking lactulose and senna; none were associated with co-danthramer. Two

\begin{tabular}{|l|l|}
\hline Level I & Systematic Reviews (Integrative/Meta-analyses/Clinical Practice Guidelines based on systematic reviews) \\
\hline Level II & Single experimental study (RCTs) \\
\hline Level III & Quasi-experimental studies \\
\hline Level IV & Non-experimental studies \\
\hline Level V & Care report/program evaluation/narrative literature reviews \\
\hline Level VI & Opinions of respected authorities/Consensus panels \\
\hline
\end{tabular}

Table 1: Classification of evidence.

\begin{tabular}{|c|c|c|c|c|}
\hline Authors & Purpose & $\begin{array}{l}\text { Sample } \\
\text { size }\end{array}$ & Outcomes/Findings & Methods \\
\hline Agra et al. [1] & $\begin{array}{l}\text { To determine treatment and cost efficacy for } \\
\text { senna and lactulose in terminal cancer patients } \\
\text { treated with opioids. }\end{array}$ & 91 & $\begin{array}{l}\text { Main outcome were defecation-free intervals } \\
\text { of } 72 \text { hours, days with defecation, general } \\
\text { health status and treatment cost. Researcher } \\
\text { recommends use of senna based on cost } \\
\text { advantage. }\end{array}$ & $\begin{array}{l}\mathrm{RCT} \text {, single-center, parallel- } \\
\text { group design. }\end{array}$ \\
\hline Portenoy et al. [17] & $\begin{array}{l}\text { To assess the efficacy and safety of } \\
\text { subcutaneous methyl naltrexone in a population } \\
\text { of patients with advanced illness and opioid- } \\
\text { induced constipation }\end{array}$ & 33 & $\begin{array}{l}\text { Laxative response (bowel movement) within } \\
4 \text { hours of dosing. Methyl naltrexone relieved } \\
\text { opioid-induced constipation at doses more than } \\
\text { or equal to } 5 \mathrm{mg} \text { in patients with advanced } \\
\text { illness, and did not reduce analgesia or cause } \\
\text { opioid withdrawal symptoms. }\end{array}$ & $\begin{array}{l}\mathrm{RCT} \text {, multi-center, parallel- } \\
\text { group design }\end{array}$ \\
\hline Ramesh et al. [18] & $\begin{array}{l}\text { To compare a liquid Ayurvedic (herbal) } \\
\text { preparation (Misrakasneham) with a } \\
\text { conventional laxative tablet (Sofsena) in the } \\
\text { management of opioid-induced constipation in } \\
\text { patients with advanced cancer. }\end{array}$ & 36 & $\begin{array}{l}\text { Researcher recommends use of misrakasneham } \\
\text { based on favorable toxicity profile and cost } \\
\text { advantage. With misrakasneham } 47 \% \text { of patients } \\
\text { have unsatisfactory bowel movement. }\end{array}$ & $\begin{array}{l}\text { RCT, single-center, } \\
\text { parallel-group design }\end{array}$ \\
\hline Slatkin et al. [20] & $\begin{array}{l}\text { To examine the safety and efficacy of a single } \\
\text { subcutaneous injection of methyl naltrexone } \\
\text { versus placebo followed by open-label active } \\
\text { treatment for up to } 4 \text { months in patients with } \\
\text { advanced illness and OIC. }\end{array}$ & 154 & $\begin{array}{l}\text { Approximately half of the methyl naltrexone } \\
\text { responders defecated within } 30 \text { minutes of } \\
\text { dosing; methyl naltrexone was efficacious in } \\
\text { rapidly inducing laxation and was generally well } \\
\text { tolerated in patients with advanced illness and } \\
\text { OIC. }\end{array}$ & $\begin{array}{l}\text { Multicenter, single-dose, } \\
\text { double-blind, randomized, } \\
\text { placebo-controlled study }\end{array}$ \\
\hline Sykes et al. [23] & & 51 & & $\begin{array}{l}\text { RCT, single-center, cross- } \\
\text { over group design }\end{array}$ \\
\hline Thomas et al. [17] & $\begin{array}{l}\text { To evaluate the safety and efficacy of methyl } \\
\text { naltrexone } 0.15 \mathrm{mg} / \mathrm{kg} \text { subcutaneously every } \\
\text { other day for two weeks. }\end{array}$ & 133 & $\begin{array}{l}\text { Methyl naltrexone significantly induced laxation } \\
\text { within four hours after the first dose compared } \\
\text { with placebo. }\end{array}$ & $\begin{array}{l}\text { RCT, multi-center, parallel- } \\
\text { group design }\end{array}$ \\
\hline
\end{tabular}

Table 2: Description of included studies. 
participants reported perianal soreness and burning while taking codanthramer. Participant preference was similar between the trial arms ( 15 for lactulose and senna and 14 for co-danthramer), but they also report that twice as many participants disliked the flavor of codanthramer compared to senna and lactulose.

Misrakasneham versus senna: One small study of 36 participants evaluated the effectiveness over two weeks of up to $10 \mathrm{ml}$ of misrakasneham versus senna $24 \mathrm{mg}$ to $72 \mathrm{mg}$ (both in liquid format).

Laxation responses: There was no statistical difference between the misrakasneham and the senna groups in satisfactory bowel movements. Six participants required rescue laxatives, of which five were in the senna group.

Constipation-associated symptoms, pain intensity, opioid withdrawal: Not evaluated.

Acceptability and tolerability: Nausea, vomiting and colicky pain were reported by two participants taking misrakasneham. None of the participants withdrew due to inefficiency. Participant preference was split between the groups.

Senna versus Lactulose: One study of 75 participants evaluated the effectiveness over four weeks of lactulose $10 \mathrm{mg}$ to $40 \mathrm{mg}$ versus senna $12 \mathrm{mg}$ to $48 \mathrm{mg}$ (both laxatives were in liquid format). Doses were increased according to clinical response.

Laxation response: there was no statistical difference between the senna and the lactulose groups in laxation response, Thirty-seven percent of participants completing the study required combined lactulose and senna to relieve constipation.

Constipation-associated symptoms, pain intensity, opioid withdrawal: there was no statistical difference in the general state of health between the trial arms.

Acceptability and tolerability: Three per trial group, reported diarrhea, vomiting and cramps. There was no significant difference in the number of participants who dropped out between the trial arms.

Methylnaltrexone versus Placebo: Two studies evaluated subcutaneous methylnaltrexone versus a placebo [20]. In one study a single dose $(0.15 \mathrm{mg} / \mathrm{kg}$ or $0.30 \mathrm{mg} / \mathrm{kg})$ of methylnaltrexone was administered; in the other study methylnaltrexone $(0.15 \mathrm{mg} / \mathrm{kg})$ was administered every other day for two weeks.

Laxation response: participants that had a laxation response at four hours were ranged from $48 \%$ to $62 \%$ in the methylnaltrexone trial groups and $13 \%$ to $15 \%$ in the placebo groups. At 24 hours it was $52 \%$ to $68 \%$ in the active trial arms and $8 \%$ to $27 \%$ in the placebo groups. A significant difference in laxation response favouring the treatment group was also found in the multi dose study at days three, five, seven, nine, eleven, and thirteen. In the single-dose study the researcher states that the study demonstrated no dose-response relationship (between $0.15 \mathrm{mg}$ and $0.3 \mathrm{mg}$ per kilogram doses) in laxation and no correlation between laxation response and baseline opioid dose. Dose response was not assessed in the other study but at day eight, if participants had fewer than three rescue-free laxation, the initial volume of the study drug was doubled (to $0.30 \mathrm{mg}$ of methylnaltrexone per kilogram).

Constipation-associated symptoms, pain intensity, opioid withdrawal: in the multi dose study they assessed pain and symptoms of opioid withdrawal using the Modified Himmelsbach Withdrawal Scale, at three time points; they found no significant difference between the trial arms. In the single-dose administration of methylnaltrexone study there was no overall change from the baseline pain scores or in having symptoms of opioid withdrawal.

Acceptability and tolerability: In the single-dose study the researcher reports that during the double- blind and subsequent openlabel phase 19 participants experienced severe adverse events that were possibly related to methylnaltrexone, with some experiencing more than one event, these were: 15 incidents of abdominal pain, three of increased sweating, two of increased pain and one each of burning at the injection site, vomiting, diarrhea, asthenia, increased blood pressure, dehydration, muscular cramps, loss of consciousness, tremor, delirium, hallucination, dyspnea and flushing. In the same study serious adverse events did not occur during the trial phase but were reported in three participants during the subsequent open-label phase. One participant had flushing and another delirium possibly related to methylnaltrexone, a third had severe diarrhoea and subsequent dehydration and cardiovascular collapse considered to be related to the drug. In the other study they report that severe adverse events occurred in $8 \%$ of participants in the methylnaltrexone group and $13 \%$ in the placebo group [21-24]. The 11 serious adverse events in those who received methylnaltrexone were: aneurysm ruptured, respiratory arrest, dyspnea exacerbated, suicidal ideation, aggression, malignant neoplasm progression, concomitant disease progression, myocardial ischemia, coronary artery disease aggravated and congestive heart failure aggravated. The investigators considered all serious adverse events as either not related or unlikely to be related to the trial drug.

Dose Ranging Trial of Methylnaltrexone: One small study of 33 participants compared the effectiveness of $1 \mathrm{mg}(\mathrm{n}=10), 5 \mathrm{mg}(\mathrm{n}=7)$, $12.5 \mathrm{mg}(\mathrm{n}=10)$ and $20 \mathrm{mg}(\mathrm{n}=6)$ of subcutaneous methylnaltrexone.

Laxation response: The study reports that the median time to laxation was 1.26 hours for patients dosed at $5 \mathrm{mg}$ or greater and in the $1 \mathrm{mg}$ group it was greater than 48 hours.

Constipation-associated symptoms, pain intensity, opioid withdrawal: The researcher reports that there was no evidence of methylnaltrexone-induced opioid withdrawal, also there was any difference in patient satisfaction scores between the dose groups.

Acceptability and tolerability: All participants experienced at least one treatment-emergent adverse event. There was no significant difference between the lower dose group compared to the other doses in the proportion of participants who had a treatment related adverse event or discontinued because of an adverse event. The types of adverse events were similar between the dose groups. The most common adverse event was abdominal pain. Two participants discontinued the trial because of an adverse event. One was an 84-year old man who withdrew due to syncope ( $12.5 \mathrm{mg}$ dose). The event was transient and resolved without sequelae; the investigators assessed that it was related to the medication. A 20-year old man was withdrawn after receiving three doses due to abdominal cramping, assessed as probably related to the study medication.

\section{Conclusion}

This review sought to determine the effectiveness of the administration of laxatives and the opioid antagonist methylnaltrexone for the management of constipation in palliative care patients. Six studies were identified. Studies either compared the effectiveness of two different laxatives, compared methylnaltrexone with a placebo or different doses of methylnaltrexone. The effectiveness of methylnaltrexone was not compared with a laxative and none of the 
Citation: Nezar ASS, Abdallah AK, Nusairat A (2016) Methylnaltrexone or laxatives for the Management of Opioid-induced Constipation among Palliative Patients on Opioid Therapy: Evidence-based Review. Adv Practice Nurs 2:121. doi: 10.4172/2573-0347.1000121

Page 4 of 4

studies compared a laxative with a placebo; all comparisons were made between different laxatives.

The review found that laxative use in the management of constipation in this patient group is based on limited research evidence; specifically, there have been no RCTs on any laxative that have evaluated laxation response rate, patient tolerability and acceptability.

There have been a few RCTs on the comparative advantages of different laxatives. The limited evidence from these studies suggests that the laxatives evaluated, including the commonly used laxatives lactulose and senna, were of similar effectiveness in this patient group. There is some evidence on the effectiveness of methylnaltrexone, indicating that in comparison to placebo and in patients where conventional laxative therapy is sub-optimal, methylnaltrexone improves laxation.

\section{References}

1. Agra Y, Sacristan A, Gonzalez M, Ferrari M, Portugues A, et al. (1998) Efficacy of senna versus lactulose in terminal cancer patients treated with opioids. J Pain Symptom Manage 15: 1-7.

2. Bouvy ML, Buurma H, Egberts TCG (2002) Laxative prescribing in relation to opioid use and the influence of pharmacy-based intervention. Journal of Clinical Pharmacy and Therapeutics 27: 107-110.

3. Candrilli SD, Davis KL, Iyer S (2009) Impact of Constipation on Opioid Use Patterns, Health Care Resource Utilization, and Costs in Cancer Patients on Opioid Therapy. J Pain Palliat Care Pharmacother 23: 231-241.

4. Chamberlain BH, Cross K, Winston JL, Thomas J, Wang W (2009) Methylnaltrexone treatment of opioid induced constipation in patients with advanced illness. J Pain Symptom Manage 38: 683-690.

5. Choi YS, Billings JA (2002) Opioid antagonists: a review of their role in palliative care, focusing on use in opioid-related constipation. J Pain Symptom Manage 24: 71-90.

6. Curtis EB, Krech R, Walsh TD (1991) Common symptoms in patients with advanced cancer. J Palliat Care 7: 25-29.

7. De Luca A, and Coupar IM (1996) Insights into opioid action in the intestinal tract. Pharmacology \& therapeutics 69: 103-115.

8. De Schepper HU, Cremonini F, Park MI, Camilleri M (2004) Opioids and the gut: pharmacology and current clinical experience. Neurogastroenterol Motil 16: 383-394.

9. Fallon MT (1999) Constipation in cancer patients: Prevalence, pathogenesis and cost-related issues. European Journal of Pain 3: 3-7.
10. Fredericks A, Hollis G, Stricker CT (2010) Diagnosis and management of opioid-induced bowel dysfunction in patients with advanced cancer. Clin J Oncol Nurs 14: 701-704

11. Holzer P (2007) Treatment of opioid-induced gut dysfunction. Expert Opin Investig Drugs 16: 181-194.

12. Holzer $P$ (2004) Opioids and opioid receptors in the enteric nervous system from a problem in opioid analgesia to a possible new prokinetic therapy in humans. Neurosci Lett 361: 192-195.

13. Melnyck BM, Fineout-Overholt E (2005) Evidence-based practice in healthcare. Philadelphia: Lippincott.

14. Mehendale SR, Yuan CS (2006) Opioid-induced gastrointestinal dysfunction Dig Dis 24: 105-112.

15. Organization, WH (1996) Cancer pain relief. (Geneva: WHO).

16. Panchal SJ, Muller-Schwefe P, Wurzelmann JI (2007) Opioid-induced bowe dysfunction: prevalence, pathophysiology and burden. Int J Clin Pract 61 : 1181-1187.

17. Portenoy RK, Thomas J, Boatwright MML, Tran D, Galasso FL, et al. (2008) Subcutaneous methylnaltrexone for the treatment of opioid-induced constipation in patients with advanced illness: a double-blind, randomized, parallel group, dose-ranging study. J Pain Symptom Manage 35: 458-468.

18. Ramesh PR, Kumar KS, Rajagopal MR, Balachandran P, Warrier PK (1998) Managing morphine-induced constipation: a controlled comparison of the ayurvedic formulation and senna. J Pain Symptom Manage 16: 240-244

19. Reimer K, Hopp M, Zenz M, Maier C, Holzer P, et al. (2009) Meeting the challenges of opioid-induced constipation in chronic pain management-a novel approach. Pharmacology 83: 10-17.

20. Slatkin N, Thomas J, Lipman AG, Wilson G, Boatwright ML, et al. (2009) Methylnaltrexone for treatment of opioid-induced constipation in advanced illness patients. J Support Oncol 7: 39-46.

21. Stetler CB, Morsi D, Rucki S, Broughton S, Corrigan B, et al. (1998) Utilizationfocused integrative reviews in a nursing service. Applied Nursing Research 11 195-206.

22. Carrie N (1991) A clinical comparison of laxatives in a hospice. Palliative Medicine 5: 307-314.

23. Sykes NP (1998) Constipation and Diarrhea. In: Doyle D, Hanks G, MacDonald $\mathrm{N}$, eds. Oxford textbook of palliative medicine. Oxford: Oxford University Press 513-526.

24. Wood JD, Galligan JJ (2004) Function of opioids in the enteric nervous system Neurogastroenterol Motil 16: 17-28. 